\title{
Cerium oxide nanoparticles sensitize non-small lung cancer cell to ionizing radiation
}

\author{
Shima Azizi 1, Arash Ghasemi 2, Hossein Asgarian-Omran 3,4, Zohreh Zal 1, Azadeh Montazeri 1,

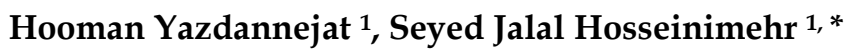 \\ 1 Department of Radiopharmacy, Faculty of Pharmacy, Mazandaran University of Medical Sciences, Sari, Iran \\ 2 Department of Radiology and Radiation Oncology, Faculty of Medicine, Mazandaran University of Medical Sciences, \\ Sari, Iran \\ 3 Department of Immunology, School of Medicine, Mazandaran University of Medical Sciences, Sari, Iran \\ 4 Immunogenetics Research Center, School of Medicine, Mazandaran University of Medical Sciences, Sari, Iran \\ * Correspondence: sjhosseinim@yahoo.com, sjhosseinim@mazums.ac.ir (S.J.H); ORCID no: 0000-0001-8055-8036
}

Received: 22 October 2017; Revised: 5 November 2017; Accepted: 8 November 2017

\begin{abstract}
Radiotherapy is an important strategy for cancer treatment, but resistance of tumor cells to ionizing radiation (IR) still remains a main challenging issue related to radiotherapy. The aim of this study was to evaluate the sensitizing effect of cerium oxide nanoparticles (CNPs) on non-small lung cancer (A-549) cells exposure to IR. A-549 cells were treated with CNPs and exposed to IR at dose 2 Gy. The radiosensitizing effect of CNPs was evaluated by clonogenic assay and flowcytometry. The findings of this study showed that CNPs reduced the frequencies of A-549 colony when these cells were exposed to IR. CNPs treatment prior exposure to IR significantly increased the IR-induced apoptotic incidences in A-549 cells. The present study demonstrates that CNPs to be an effective sensitizer on apoptosis and cell death induced by IR in A-549 cells.
\end{abstract}

KEYWORDS: Cerium oxide nanoparticle, nanoceria, radiosensitizing, apoptosis, ionizing radiation, radiosensitizer.

\section{INTRODUCTION}

Ionizing radiation (IR) is widely used for cancer treatment. In this strategy, IR is delivered to cancer cells and produces several toxic substances such as reactive oxygen species (ROS) and free radicals that have killing effects on cancer cells. Although IR induces apoptosis and death in cancerous cells, these cells may be resistant to IR. For beating on IR-resistance of cancerous cells, delivering of IR at high dose is recommended that results in side effects on normal tissue [1]. Since IR does not distinct between cancer and normal cells, IR induces side effects to normal tissues and it is usually a dose-limiting factor in radiation therapy [2]. The radiation-induced free radicals that attach to DNA sites resulted in chemically fixed damage in the presence of oxygen. This fixed DNA damage leading to an enhanced cell death. Then cells under hypoxia are more resistance to IR than normoxic cells. Tumor hypoxia is mainly caused by insufficient tumor angiogenesis and oxygen supply during tumor growth. Then oxygen content in cells is a crucial factor in radiosenstizing effect of IR on killing cells [3]. The biology of normal and tumor cells are different. ROS is mostly known to be involved in tumor induction and progression process but also enhance tumor cell radiosensitivity. The combined use of antioxidants and radiation enhance overproduction of ROS in tumor cells leading to enhanced radiosensitivity [4]. While the combined antioxidant with IR leading to protect normal cells against toxicity induced by IR [5,6]. Radiosensitizers are used in radiation therapy for improvement of IR susceptibility of cancer cells. Radiotherapy can be applied at doses sufficiently low to minimize damage to neighbor normal tissues $[7,8]$. Radiotherapy is an important treatment protocol for the

How to cite this article: Azizi S, Ghasemi A, Asgarian-Omran H, Zal Z, Montazeri A, Yazdannejat H, Hosseinimehr SJ. Cerium oxide nanoparticles sensitize non-small lung cancer cell to ionizing radiation. Marmara Pharm J. 2018; 22 (2): 307-313.

(C) 2018 Marmara University Press

ISSN : 1309-0801

https://doi.org/10.12991/mpj.2018.68

Marmara Pharm J 2018; 22(2): 307-313 
management of non-small cell lung cancer (NSCLC). However, radioresistance of cancer cells markedly impairs the effects of radiotherapy in patients. There is a great interest in the use of radiosensitizers that improve the cancer treatment with radiotherapy $[9,10]$. Radiosensitzers are enabling to imbalance cellular oxygen and sensitize tumor cells to IR [11, 12]. $\mathrm{CeO}_{2}$ cerium oxide nanoparticle (nanoceria, CNP) is developed as a therapeutic agent for oxidative stress associated diseases due to its antioxidant properties. Cerium is rare metal, when combined with oxygen, can form a particle that has highly contribution in oxidative stress process in cells. Some studies have shown CNP to possess anti-cancer effects [13-16]. CNP can change intracellular oxidative stress status that is partially attributed to the prooxidant activity of the CNP. Elevated ROS induces cell damages might eventually lead to the cancerous cell death [17]. CNPs inhibited the migration and proliferation of gastric cancer cells [14].

The ability of CNPs to modulation ROS could participate to their biological properties for improvement of radiotherapy in cancer treatment. Several studies exhibited that CNPs protected human normal cells against oxidative stress through antioxidant and anti-inflammatory process [18-21]. In radiotherapy regimen in patients with NSCLC, lung of patients is exposed to IR then normal and cancerous lung cells are encountered to free radicals and toxic substances results in cellular damages. It is clear that CNPs protect normal lung cells against oxidative stress; it is interesting to evaluate the effect of CNPs on radiation-induced toxicity in lung cancer cells [18].

Thus, the present study attempts to investigate the sensitizing effect of CNPs on IR-induced apoptosis and cell death in non-small cell lung cancer cells (A-549). These results demonstrate CNPs are potentially radiation sensitizer for the treatment of human lung cancer.

\section{RESULTS}

\subsection{Effect of CNPs on the clonogenic survival of irradiated A-549 cells}

The numbers of A-549 colonies in control and treated groups are shown in figure 1. Figure 2 shows a significant ( $p<0.001)$ decrease in survival colony of irradiated A-549 cells $(36 \% \pm 6)$ as compared to the untreated control group $(68 \% \pm 5)$. On the other hand, when cells were treated to CNPs at concentration $50 \mu \mathrm{g} / \mathrm{ml}$ for three hours it showed a significantly reduction on the number of colonies $(31 \% \pm 6)$ as compared to control cells. CNPs treatment resulted insignificantly reduction on the survival clones in A-549 cells as compared to irradiated cells alone. Addition of CNPs to A-549 cells before exposure to IR resulted in a significantly reduction in survival clones $(7 \% \pm 1)$ as compared to irradiated cells and CNPs treated cells alones $(p<0.001)$ (Figure 2).

\subsection{Apoptosis in A-549 cells treated with CNPs and radiation}

To investigate the apoptotic effect of CNPs-induced radiosensitization, flow cytometry was used for measurement of apoptosis in A-549 (Figure 3). As shown in figure 4, compared to the control group $(1.7 \% \pm 0.4)$, the apoptosis rate of A-549 cells was increased in CPNs-alone group $(4.1 \% \pm 0.4)$ and IR-alone group $(3.4 \% \pm 0.2)$ $(P<0.01)$. It was observed an insignificantly difference between CPNs and IR groups in induction of apoptosis in A-549 cells. Furthermore, the apoptosis rate was significantly increased in CPNs + IR combination group $(6.5 \% \pm$ $0.5)$ compared to the IR alone and CPNs alone groups $(P<0.05)$.

\section{DISCUSSION}

This study demonstrated that CNPs have radiosensitizing effects on tumor cells by cell deaths and apoptosis induced by X-ray in A-549 cells. In this study, CNPs significantly reduced the number of colonies in irradiated A-549 cells. The number of colony was reduced to $7 \%$ in CNPs + IR group as compared to $31 \%$ and $36 \%$ with CNPs and IR alone. CNPs are known for their anticancer effects [22, 23]. CNPs change intracellular redox status which is partly attributed to the prooxidant activity of the CNPs in cancerous cells [24, 25]. Elevated ROS induces cell damages that might eventually lead to the cell death in cancerous cells treated with CNPs. CNPs induced the generation of ROS and malondialdehyde, and decreasing of superoxide dismutase and glutathione levels in human skin melanoma cells [25]. Mittal and Pandey reported that CNPs are enable to increase the intracellular ROS levels and induce DNA damage and cell deaths in A-549 cells [24]. Although, cancerous cell lines were sensitive to CNPs treatment, normal cell lines (keratinocytes and fibroblasts cells) were insensitive [17]. 


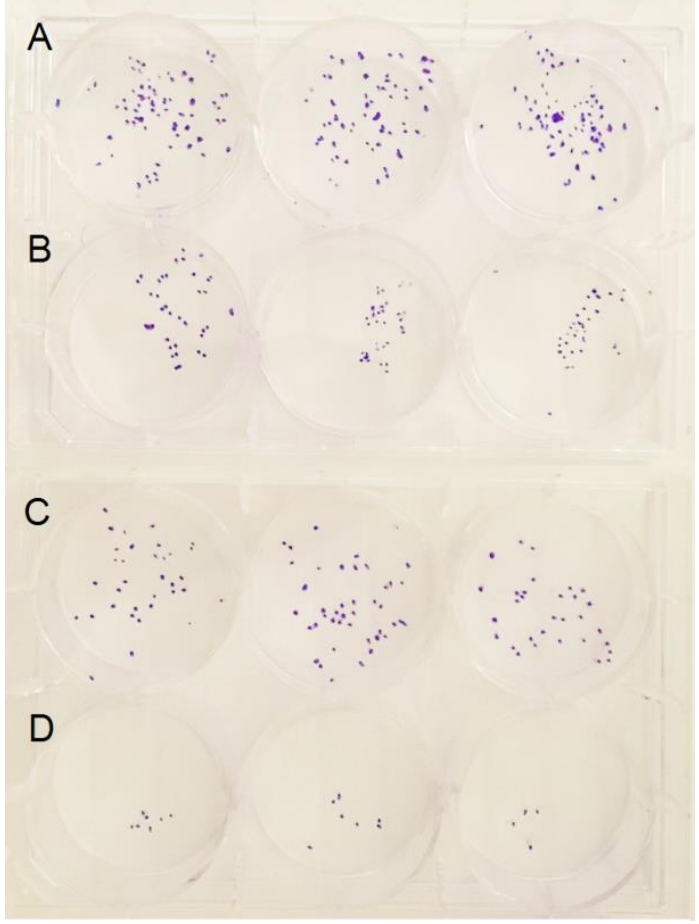

Figure 1. Effect of cerium oxide nanoparticles (CNPs) on the clonogenic survival of irradiated A-549 cells. Cells were treated with CNPs at concentration $50 \mu \mathrm{g} / \mathrm{ml}$ for three hours and irradiated with X-rays at dose $2 \mathrm{~Gy}$. A; control, B: CNPs, C: ionizing radiation (IR), D: CNPs + IR.

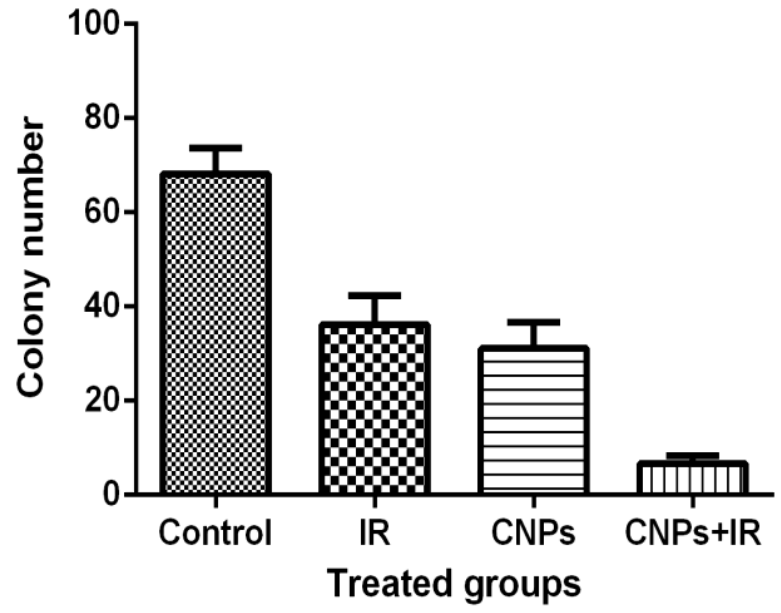

Figure 2. Effect of cerium oxide nanoparticles (CNPs) on the clonogenic survival of irradiated A-549 cells. Cells were treated with CNPs at concentration $50 \mu \mathrm{g} / \mathrm{ml}$ for three hours and irradiated with X-rays at dose $2 \mathrm{~Gy}$. At the end of 15 day incubation, survival colonies from each group were scored. One hundred cells were seeded cells and then numbers of colonies were counted. Values were mean $\pm \mathrm{SD}(\mathrm{N}=3)$.

Colon et al. reported that CNPs protected the gastrointestinal epithelium against radiation-induced damage through acting as free-radical scavengers and increasing the production of superoxide dismutase [26]. Other studies showed the radioprotective effects of CNPs in human normal cells and animal model [27, 28]. CNPs exhibited antioxidant properties through different mechanisms such as free radical scavenging, reducing ROS level and increase endogenous antioxidants [19, 26, 29]. These antioxidant mechanisms are associated to protection cells against DNA damage and deaths induced by IR. The antioxidant activities of CNPs are responsible for its radioprotection. CNPs display minimal toxicity to normal tissues and provide protection from various forms of oxidative stress disorders [23]. In normal lung cells, CNPs have cytoprotective and antioxidative effects [18].

These nano particles prevented normal epithelium oxidation and inhibit inflammatory process [18, 20, 21]. However CNPs have antioxidant activity and anti-inflammatory activities, these effects are leading different results in normal and cancerous cells. Several studies demonstrated that antioxidants have radioprotective effects on normal cells by mainly decreases ROS levels while these compounds have radiosensitive effects in tumor cells by increasing ROS levels. Curcumin as a powerful antioxidant has radioprotective effect on normal cells [30], while it has radiosensitizing effect in tumor cells by increasing ROS level and suppressing inflammatory process such as NF-kB activation pathway induced by ionizing radiation [31-33]. Genestein has antioxidant activity and protect healthy cell against toxicity induced by IR [34, 35]. Genistein stimulated irradiation-induced intracellular reactive oxygene and suppressed irradiation-induced COX-2 expression, as an inflammation marker, resulted in radiosensitizing effect in cancerous cells [36]. The combined with radiation, genistein increased the ROS levels in A-549 cells and significantly increased cell apoptosis in A-549 [37]. The dual capabilities of CNPs to act as an oxidant in cancer cells, yet antioxidant in normal cells, supports the role of CNPs as an promising agent for radiotherapy that could significantly improve cancer treatment. 

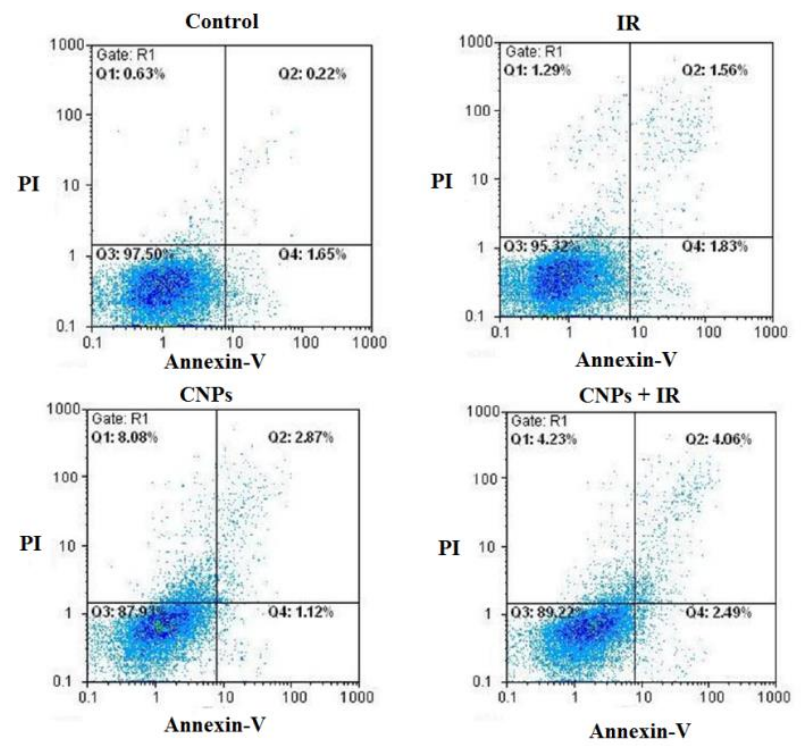

Figure 3. Effect of cerium oxide nanoparticles (CNPs; $50 \mu \mathrm{g} / \mathrm{ml}$ ) on radiation-induced apoptosis in A-549 cells. Cells were analyzed for Annexin V binding and for PI uptake using flow cytometry. Representative dot plots of one set of five independent experiments of Annexin $\mathrm{V}$ and PI staining is shown. In each figure, the lower left quadrant (Annexin $\mathrm{V}^{-}$and $\mathrm{PI}^{-}$) was considered as live cells, the lowerright quadrant (Annexin $\mathrm{V}^{+}$and $\mathrm{PI}^{-}$) was considered as apoptotic cells, the upper right quadrant (Annexin $\mathrm{V}^{+}$ and $\mathrm{PI}^{+}$) was considered as late apoprotic and necrotic cells $(\mathrm{N}=3)$.

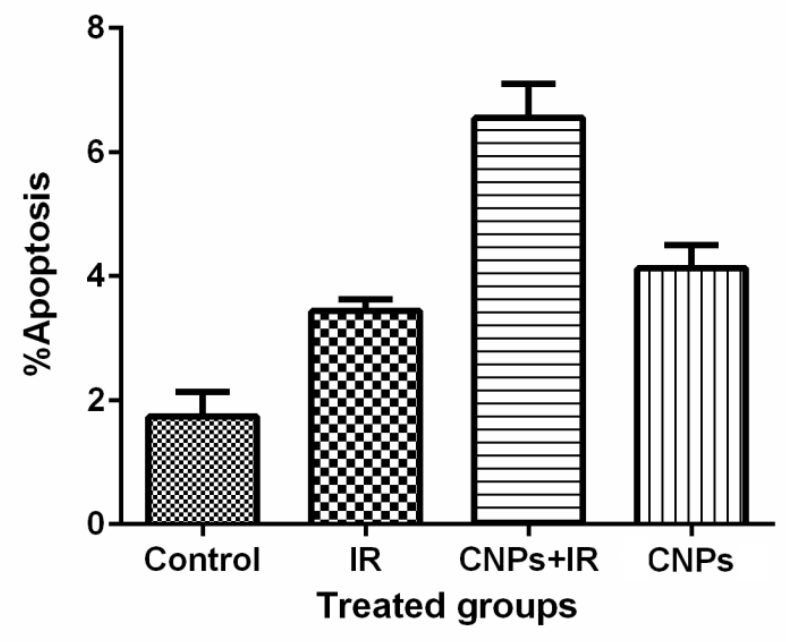

Figure 4. Effect of cerium oxide nanoparticles (CNPs; 50 $\mu \mathrm{g} / \mathrm{ml}$ ) on ionizing radiation (IR)-induced apoptosis in A549 cells. The percentages of apoptotic cells were shown in experimental groups. Values are expressed as mean \pm SD of three experiments. $P<0.05: 2$ Gy group alone compared to sham control, CNPs+ 2 Gy and CNPs groups.

\section{CONCLUSION}

We demonstrated that the cerium oxide nanoparticles sensitized human lung cancer A-549 cells to radiation-induced apoptosis and death. This result provides a new indication of CNPs for sensitizing of A-549 cancer cells to radiation therapy in patients. Since the protection of normal cell against toxicity induced by IR, future study is necessary to perform for possible radioprotection of CNPs on healthy cell.

\section{MATERIAL AND METHODS}

\subsection{Materials}

A-549 cell line was obtained from the National Center for Genetic and biological reserves of Iran and cultured at $37^{\circ} \mathrm{C}$ and 5\% $\mathrm{CO}_{2}$ in. Dulbecco's Modified Eagle Medium (DMEM) (Gibco, Paisley, UK) supplemented with $10 \%$ fetal bovine serum (FBS) (Gibco, UK) and $100 \mu \mathrm{g} / \mathrm{mL}$ penicillin-streptomycin (Gibco, UK). Annexin-VFLUOS Staining Kit was obtained from eBioscienc (USA). Cerium oxide nanoparticle was obtained from Neutrino Co., (Iran). Particle size was $378 \mathrm{~nm}$, with polydispersity index (PDI) 0.372 and Zeta -7.11 that were determined with Zetasizer 3600 Nano ZS (Malvern Instrument Ltd, Malvern, UK).

\subsection{Clonogenic assay}

A-549 cells were plated in 6-well dishes (100 cells in dish), grown for 24 hours and then treated with CNPs $(50 \mu \mathrm{g} / \mathrm{ml})$ for three hours. This concentration of CNPs was selected from other study that CNPs were not 
exhibited any toxicity on epithelial normal lung cell line (BEAS-2B) during 24 and $48 \mathrm{~h}$ exposure to these particles at concentration $50 \mu \mathrm{g} / \mathrm{ml}$ [18]. The CNPs-treated cells were exposed to IR at dose of $2 \mathrm{~Gy}$ with $6 \mathrm{MV}$ X-ray beam produced by a Linear accelerator (Siemens, Primus, Germany) at a dose rate of $1.9 \mathrm{~Gy} / \mathrm{min}$. After exposure to IR, cells were incubated in complete culture medium for up to 15 days, colonies were washed with $1 \times$ PBS and then were fixed with $1 \%$ glutaraldehyde for $30 \mathrm{~min}$ and were stained with $0.5 \%$ crystal violet (wt/vol) in water. The colony containing at least 50 cells was scored and considered to cell alive. The other groups as control (without CNPs treatment and exposure to IR), CNPs (treatment with CNPs, without exposure to IR) and IR (only exposure to IR) were treated at same manner to above protocol.

\subsection{Apoptosis determination by flow cytometry}

Apoptotic cells were analyzed $24 \mathrm{~h}$ after exposure of cells to IR. A-549 cells $\left(2 \times 10^{5}\right)$ were treated with CPNs at concentration $50 \mu \mathrm{g} / \mathrm{ml}$ for three hours in 12-well plates and then were exposed to IR at dose 2 Gy. Cells were cultured in DMEM medium for $24 \mathrm{~h}$. Apoptosis were determined using an 'Annexin-V-FLUOS Staining Kit' according to the manufacturer's instruction (eBioscience, USA). Briefly, cells were washed with PBS and incubated with Annexin-V FLUOS labeling solution (containing $2 \mu \mathrm{L}$ Annexin-V-FLUOS labeling reagent and $2 \mu \mathrm{L}$ propidium iodide (PI) solution in $100 \mu \mathrm{L}$ incubation buffer for each sample) at room temperature in the dark for 15 min. Following incubation, analysis was performed with a Partec flow cytometer system and Flomax software (Partec, Germany). Non-stained cells were used as negative control for background determination. For each sample, a minimum of 10000 events were counted and analyzed.

\subsection{Statistical analysis}

The data values are presented as means \pm standard division (SD). Statistical analysis was performed using one-way analysis of variance (ANOVA), as well as Tukey's multiple comparison and Dunnett multiple comparison tests. $P$ value $<0.05$ was considered as significant and highly significant (Prism 7 Software, 2016, USA).

Acknowledgments: This study was supported by a grant from Mazandaran University of Medical Sciences, Sari, Iran. Seyed Jalal Hosseinimehr was received this grant.

Author contributions: Concept - S.J.H.; Design - S.J.H., S.A., H.S.O.; Supervision - S.J.H.; Resource - S.J.H.; Materials - S.A.; Data Collection \&/or Processing - S.A., A.G., H.A.O., Z.Z., A. M., H.Y.; Analysis \&/or Interpretation - S.A., H.A.O., S.J.H.; Literature Search - S.A., S.J.H.; Writing - S.J.H; Critical Reviews - S.A., A.G., S.J.H., H.A.O., Z.Z., H.Y., A.M.

Conflict of Interest: All Authors reported no potential conflict of interest relevant to this article.

\section{REFERENCES}

[1] Salehifar E, Hosseinimehr SJ. The use of cyclooxygenase-2 inhibitors for improvement of efficacy of radiotherapy in cancers. Drug Discov Today. 2016; 21(4): 654-662.

[2] Hosseinimehr SJ. Trends in the development of radioprotective agents. Drug Discov Today. 2007; 12(19-20): 794-805.

[3] Orlowski K, Rohrer Bley C, Zimmermann M, Vuong V, Hug D, Soltermann A, Broggini-Tenzer A, Pruschy M. Dynamics of tumor hypoxia in response to patupilone and ionizing radiation. PLoS One. 2012; 7(12): e51476.

[4] Dayal R, Singh A, Pandey A, Mishra KP. Reactive oxygen species as mediator of tumor radiosensitivity. J Cancer Res Ther. 2014; 10(4): 811-818.

[5] Hosseinimehr SJ, Azadbakht M, Mousavi SM, Mahmoudzadeh A, Akhlaghpoor S. Radioprotective effects of hawthorn fruit extract against gamma irradiation in mouse bone marrow cells. J Radiat Res (Tokyo). 2007; 48(1): 63-68.

[6] Hosseinimehr SJ, Mahmoudzadeh A, Ahmadi A, Mohamadifar S, Akhlaghpoor S. Radioprotective effects of hesperidin against genotoxicity induced by gamma-irradiation in human lymphocytes. Mutagenesis. 2009; 24(3): $233-235$.

[7] Linkous AG, Yazlovitskaya EM. Novel radiosensitizing anticancer therapeutics. Anticancer Res. 2012 ; 32(7): $2487-2499$.

[8] Nishino K, Tanamachi K, Nakanishi Y, Ide S, Kojima S, Tanuma S, Tsukimoto M. Radiosensitizing Effect of TRPV1 Channel Inhibitors in Cancer Cells. Biol Pharm Bull. 2016; 39(7): 1224-1230. 
[9] Provencio M, Sanchez A. Therapeutic integration of new molecule-targeted therapies with radiotherapy in lung cancer. Transl Lung Cancer Res. 2014; 3(2): 89-94.

[10] Jeremic B. Radiation therapy. Hematol Oncol Clin North Am. 2004; 18(1): 1-12.

[11] Clarke RH, Moosa S, Anzivino M, Wang Y, Floyd DH, Purow BW, Lee KS. Sustained radiosensitization of hypoxic glioma cells after oxygen pretreatment in an animal model of glioblastoma and in vitro models of tumor hypoxia. PLoS One. 2014; 9(10): e111199.

[12] Malik A, Sultana M, Qazi A, Qazi MH, Parveen G, Waquar S, Ashraf AB, Rasool M. Role of natural radiosensitizers and cancer cell radioresistance: An update. Anal Cell Pathol (Amst). 2016; $2016(6146595$.

[13] Li C, Zhao W, Liu B, Xu G, Liu L, Lv H, Shang D, Yang D, Damirin A, Zhang J. Cytotoxicity of ultrafine monodispersed nanoceria on human gastric cancer cells. J Biomed Nanotechnol. 2014; 10(7): 1231-1241.

[14] Xiao YF, Li JM, Wang SM, Yong X, Tang B, Jie MM, Dong H, Yang XC, Yang SM. Cerium oxide nanoparticles inhibit the migration and proliferation of gastric cancer by increasing DHX15 expression. Int J Nanomedicine. 2016; 11: 3023-3034.

[15] Asati A, Santra S, Kaittanis C, Perez JM. Surface-charge-dependent cell localization and cytotoxicity of cerium oxide nanoparticles. ACS Nano. 2010; 4(9): 5321-5331.

[16] Lin W, Huang YW, Zhou XD, Ma Y. Toxicity of cerium oxide nanoparticles in human lung cancer cells. Int J Toxicol. 2006; 25(6): 451-457.

[17] Pesic M, Podolski-Renic A, Stojkovic S, Matovic B, Zmejkoski D, Kojic V, Bogdanović G, Pavićević A, Mojović M, Savić A, Milenković I, Kalauzi A, Radotić K. Anti-cancer effects of cerium oxide nanoparticles and its intracellular redox activity. Chem Biol Interact. 2015; 232:85-93.

[18] Rubio L, Annangi B, Vila L, Hernandez A, Marcos R. Antioxidant and anti-genotoxic properties of cerium oxide nanoparticles in a pulmonary-like cell system. Arch Toxicol. 2016; 90(2): 269-278.

[19] Niu J, Wang K, Kolattukudy PE. Cerium oxide nanoparticles inhibit oxidative stress and nuclear factor-kappaB activation in H9c2 cardiomyocytes exposed to cigarette smoke extract. J Pharmacol Exp Ther. 2011; 338(1): 53-61.

[20] Xia T, Kovochich M, Liong M, Madler L, Gilbert B, Shi H, Yeh JI, Zink JI, Nel AE. Comparison of the mechanism of toxicity of zinc oxide and cerium oxide nanoparticles based on dissolution and oxidative stress properties. ACS Nano. 2008; 2(10): 2121-2134.

[21] Arya A, Sethy NK, Singh SK, Das M, Bhargava K. Cerium oxide nanoparticles protect rodent lungs from hypobaric hypoxia-induced oxidative stress and inflammation. Int J Nanomedicine. 2013; 8:4507-4520.

[22] Alili L, Sack M, von Montfort C, Giri S, Das S, Carroll KS, Zanger K, Seal S, Brenneisen P. Downregulation of tumor growth and invasion by redox-active nanoparticles. Antioxid Redox Signal. 2013; 19(8): 765-778.

[23] Gao Y, Chen K, Ma JL, Gao F. Cerium oxide nanoparticles in cancer. Onco Targets Ther. 2014; 7(835-840.

[24] Mittal S, Pandey AK. Cerium oxide nanoparticles induced toxicity in human lung cells: role of ROS mediated DNA damage and apoptosis. Biomed Res Int. 2014; 2014(891934.

[25] Ali D, Alarifi S, Alkahtani S, AlKahtane AA, Almalik A. Cerium Oxide nanoparticles induce oxidative stress and genotoxicity in human skin melanoma cells. Cell Biochem Biophys. 2015; 71(3): 1643-1651.

[26] Colon J, Hsieh N, Ferguson A, Kupelian P, Seal S, Jenkins DW, Baker CH. Cerium oxide nanoparticles protect gastrointestinal epithelium from radiation-induced damage by reduction of reactive oxygen species and upregulation of superoxide dismutase 2. Nanomedicine. 2010; 6(5): 698-705.

[27] Tarnuzzer RW, Colon J, Patil S, Seal S. Vacancy engineered ceria nanostructures for protection from radiation-induced cellular damage. Nano Lett. 2005; 5(12): 2573-2577.

[28] Madero-Visbal RA, Alvarado BE, Colon JF, Baker CH, Wason MS, Isley B, Seal S, Lee CM, Das S, Manon R. Harnessing nanoparticles to improve toxicity after head and neck radiation. Nanomedicine. 2012; 8(7): 1223-1231.

[29] Zhou X, Wong LL, Karakoti AS, Seal S, McGinnis JF. Nanoceria inhibit the development and promote the regression of pathologic retinal neovascularization in the Vldlr knockout mouse. PLoS One. 2011; 6(2): e16733. 
[30] Shafaghati N, Hedayati M, Hosseinimehr SJ. Protective effects of curcumin against genotoxicity induced by 131-iodine in human cultured lymphocyte cells. Pharmacogn Mag. 2014; 10(38): 106-110.

[31] Javvadi P, Segan AT, Tuttle SW, Koumenis C. The chemopreventive agent curcumin is a potent radiosensitizer of human cervical tumor cells via increased reactive oxygen species production and overactivation of the mitogen-activated protein kinase pathway. Mol Pharmacol. 2008; 73(5): 1491-1501.

[32] Orr WS, Denbo JW, Saab KR, Ng CY, Wu J, Li K, Garner JM, Morton CL, Du Z, Pfeffer LM, Davidoff AM. Curcumin potentiates rhabdomyosarcoma radiosensitivity by suppressing NF-kappaB activity. PLoS One. 2013; 8(2): e51309.

[33] Hosseinimehr SJ, Hosseini SA. Radiosensitive effect of curcumin on thyroid cancer cell death induced by radioiodine131. Interdiscip Toxicol. 2014; 7(2): 85-88.

[34] Kim JS, Heo K, Yi JM, Gong EJ, Yang K, Moon C, Kim SH. Genistein mitigates radiation-induced testicular injury. Phytother Res. 2012; 26(8): 1119-1125.

[35] Rahman Mazumder MA, Hongsprabhas P. Genistein as antioxidant and antibrowning agents in in vivo and in vitro: A review. Biomed Pharmacother. 2016; 82(379-392.

[36] Shin JI, Shim JH, Kim KH, Choi HS, Kim JW, Lee HG, Kim BY, Park SN, Park OJ, Yoon DY. Sensitization of the apoptotic effect of gamma-irradiation in genistein-pretreated CaSki cervical cancer cells. J Microbiol Biotechnol. 2008; 18(3): 523531.

[37] Liu X, Sun C, Liu B, Jin X, Li P, Zheng X, Zhao T, Li F, Li Q. Genistein mediates the selective radiosensitizing effect in NSCLC A549 cells via inhibiting methylation of the keap1 gene promoter region. Oncotarget. 2016; 7(19): 27267-27279.

This is an open access article which is publicly available on our journal's website under Institutional Repository at http://dspace.marmara.edu.tr. 